\title{
AKTIVITAS TABIR SURYA FRAKSI N-HEKSANA BUAH LIBO BERDASARKAN NILAI SPF
}

\author{
Ihdina Aulia, Welinda Dyah Ayu, Rolan Rusli* \\ Laboratorium Penelitian dan Pengembangan Farmaka Tropis \\ Fakultas Farmasi Universitas Mulawarman \\ email: rolan@farmasi.unmul.ac.id
}

\begin{abstract}
ABSTRAK
Libo (Ficus variegata Blume.) merupakan tumbuhan liar yang telah diketahui berpotensi sebagai sumber antioksidan potensial. Semakin baik aktivitas antioksidan suatu senyawa maka semakin besar pula nilai sun protection factor (SPF) dari senyawa tersebut. Penentuan kategori tabir surya dan nilai SPF fraksi n-heksana buah libo dilakukan secara in-vitro menggunakan spektrofotometer UV-VIS. Konsentrasi terbaik untuk kategori tabir surya fraksi $n$-heksana adalah 300 dan 400 ppm. Berdasarkan nilai \% Te dan \% Tp, fraksi nheksana termasuk kategori perlindungan ekstra dan sunblock. Sedangkan berdasarkan nilai SPF > 20 menunjukkan bahwa fraksi n-heksana termasuk ke dalam kategori proteksi ultra dalam efektivitas tabir surya.
\end{abstract}

Kata kunci: Ficus variegata Blume., antioksidan, aktivitas tabir surya, \% Te, \% Tp, SPF

\begin{abstract}
Libo (Ficus variegata Blume.) is a wild plant that has been known as a source potential antioxidants. The greater value of Antioxidant activity in compound have the better value of sun protection factor (SPF). Determination Libo fruit of category sunscreen and SPF value of $n$-hexane fraction was performed in vitro using a UV-VIS spectrophotometer. Concentration of the best category sunscreen of n-hexane fraction was 300 and 400 ppm. Based on value of \%Te and \%Tp show that n-hexane fraction as category of protection extra and sunblock. Whilst SPF value was $>20$ show that n-hexane fraction as category of ultraprotection in the effectiveness of sunscreens.
\end{abstract}

Key words: Ficus variegata Blume., antioxidant, sunscreen activity, \% Te, \% Tp, SPF

\section{PENDAHULUAN}

Indonesia merupakan negara yang terletak di daerah tropis yang memiliki intensitas cahaya sinar matahari yang tinggi. Paparan sinar matahari yang kuat dapat menyebabkan eritema dan sunburn (kulit terbakar), sedangkan paparan sinar matahari yang berlebihan dan berlangsung lama menyebabkan degenerasi pada kulit seperti penuaan dini dan beberapa kanker kulit (Hadinoto, dkk., 2000). World Health Organization (WHO) mengemukakan 
jumlah penderita kanker di dunia setiap tahun bertambah sekitar 7 juta orang, dan dua per tiga diantaranya berada di negara-negara yang sedang berkembang. Jika tidak dikendalikan, diperkirakan 26 juta orang akan menderita kanker dan 17 juta meninggal karena kanker pada tahun 2030 (WHO, 2008).

Berbagai cara dapat dilakukan untuk melindungi manusia dari sinar ultraviolet (UV) (Wilkinson dan Moore, 1982). Tabir surya adalah suatu sediaan yang mengandung senyawa kimia yang dapat menyerap, menghamburkan atau memantulkan sinar surya yang mengenai kulit sehingga dapat digunakan untuk melindungi fungsi dan struktur kulit manusia dari kerusakan akibat sinar surya (FDA, 2003).

Senyawa dalam tabir surya mampu melindungi kulit karena adanya ikatan yang dapat saling berkonjugasi sehingga ikatan tersebut akan beresonansi saat terpapar sinar UV sehingga akan menurunkan energi dan bersifat melindungi kulit. (Handayani, 2009).

Pada dekade terakhir ini, ada suatu peningkatan penggunaan penggunaan fitokimia antioksidan dalam tabir surya yang sekaligus mampu bertindak sebagai fotoprotektif. Antioksidan dari sumber alami dapat menyediakan berbagai kemungkinan baru untuk pengobatan, perawatan dan pencegahan penyakit yang disebabkan oleh cahaya ultraviolet (Budiarso, 2015).

Beberapa penelitian yang berhubungan dengan kefarmasian terhadap Libo (Ficus variegata Blume.) telah dilakukan dan diketahui Libo berpotensi sebagai sumber antioksidan yang potensial dimana seluruh ekstrak menunjukkan nilai $\mathrm{IC}_{50}$ di bawah 100 ppm (Rijai, 2013). Lebih lanjut, Rusli, dkk (2015) menyebutkan bahwa fraksi isolat $n$ heksana daun Libo memiliki kandungan alkaloid, flavonoid, dan steroid atau triterpenoid dan memiliki aktivitas antioksidan. Berdasarkan hal tersebut maka dilakukan penelitian mengenai aktivitas tabir surya fraksi $n$-heksana buah Libo.

\section{METODE PENELITIAN}

\section{Alat dan Bahan}

Alat yang digunakan yaitu timbangan analitik, rotary evaporator, corong pisah, kuvet kuarsa, spektrofotometer UV-Vis double beam (Dynamica Halo DB-20S), labu ukur, pipet ukur, alat-alat kaca dan non kaca. Bahan yang digunakan yaitu buah tumbuhan Libo, aquades, metanol, $n$-heksana.

\section{Prosedur Kerja}

\section{Penyiapan sampel}

Buah Libo (Ficus variegata Blume.) yang telah tua dikumpulkan dan dibuat menjadi simplisia. Simplisia buah Libo dimaserasi dengan pelarut $n$-heksana. Kemudian filtrat disaring dan residu dimaserasi kembali dengan pelarut metanol selama 6 hari pada suhu kamar sambil sesekali diaduk dimana pergantian pelarut dilakukan setiap 2 hari sekali. Filtrat disaring dan dipekatkan dengan rotary evaporator sehingga diperoleh ekstrak kasar metanol. Ekstrak kasar metanol kemudian ditambah aquades lalu difraksinasi dengan $n$-heksana sehingga diperoleh ekstrak fraksi $n$-heksana. 


\section{Pengujian Aktivitas Tabir Surya Fraksi $n$-heksana Buah Libo}

\section{a. Penentuan $\%$ transmisi eritema dan \% transmisi pigmentasi}

Penentuan profil kategori aktivitas tabir surya ditentukan secara in-vitro dengan metode spektrofotometri (Balsam dan Sagarin, 1972). Fraksi $n$-heksana dilarutkan dalam metanol kemudian dibuat dalam 7 seri konsentrasi yaitu 50, 100, 150, 200, 250, 300 dan 400 ppm. Lalu masing-masing konsentrasi diukur absorbansinya dengan menggunakan spektrofotometer UV-Vis pada panjang gelombang yang dapat menimbulkan eritema dan pigmentasi yaitu 292,5-372,5 nm dengan interval $5 \mathrm{~nm}$ dan dilakukan tiga kali pengulangan. Nilai transmisi $(\mathrm{T})$ dapat dihitung dengan persamaan 1.

$$
\mathrm{A}=-\log \mathrm{T}
$$
persamaan 1

Transmisi Eritema (Te) dihitung menggunakan persamaan 2.

$$
\mathrm{Te}=\mathrm{T} \times \mathrm{Fe}
$$
persamaan 2

dimana $\mathrm{Fe}$ adalah fluks eritema yang nilainya pada panjang gelombang tertentu dan merupakan nilai tetapan. Banyaknya Fe yang diteruskan oleh tabir surya (Ee) dihitung menggunakan rumus persamaan 3 .

$$
\mathrm{Ee}=\sum \mathrm{Te}
$$

sedangkan persen transmisi eritema (\% Te) dengan persamaan 4.

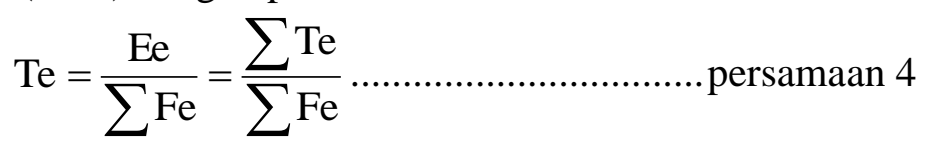

Perolehan nilai Transmisi dilakukan melaui perhitungan Transmisi pigmentasi (Tp) dihitung dengan persamaan 5 .

$$
\mathrm{Tp}=\mathrm{T} \times \mathrm{Fp}
$$
persamaan 5

dimana Fp adalah fluks pigmentasi yang nilainya pada panjang gelombang tertentu merupakan nilai tetapan. Banyaknya Fp pigmentasi yang diteruskan oleh tabir surya (Ep) dihitung dengan rumus persamaan 6 .

$$
\mathrm{Ep}=\sum \mathrm{Tp}
$$
persamaan 6

Sedangkan persen transmisi pigmentasi (\% Tp) dihitung dengan persamaan 7.

$$
\mathrm{Tp}=\frac{\mathrm{Ep}}{\sum \mathrm{Fp}}=\frac{\sum \mathrm{Tp}}{\sum \mathrm{Fp}}
$$

Dimana:

$\mathrm{T}$ : Transmisi

Te : Transmisi eritema

$\mathrm{Fe}$ : Fluks eritema yang nilainya pada panjang gelombang tertentu

Ee : Banyaknya fluks eritema yang diteruskan oleh tabir surya

Tp : Transmisi pigmentasi

Fp : Fluks pigmentasi yang nilainya pada panjang gelombang tertentu

Ep : Banyaknya fluks pigmentasi yang diteruskan oleh tabir surya 
Tabel 1. Kategori Penilaian Aktivitas Tabir Surya

\begin{tabular}{lcc}
\hline \multirow{2}{*}{ Kategori } & \multicolumn{2}{c}{$\%$ Transmisi } \\
\cline { 2 - 3 } & Eritema & Pigmentasi \\
\hline Sunblock & $<1$ & $3-40$ \\
Proteksi ekstra & $1-6$ & $42-86$ \\
Suntan standar & $6-12$ & $45-86$ \\
Fast tanning & $10-18$ & $45-86$ \\
\hline
\end{tabular}

\section{Penentuan Nilai SPF}

Penentuan efektivitas tabir surya dilakukan dengan menghitung nilai SPF secara invitro dengan metode spektrofotometri (Mansur et al, 1986). Masing-masing konsentrasi diukur nilai absorbansi (A) pada panjang gelombang 290-320 nm dengan interval $5 \mathrm{~nm}$ dan dilakukan tiga kali pengulangan.

Nilai SPF dihitung dengan persamaan 8 .

$$
\mathrm{SPF}=\mathrm{CF} \times \sum_{290}^{320} \mathrm{EE}(\lambda) \times \mathrm{I}(\lambda) \times \operatorname{Abs}(\lambda)
$$

Dimana :

$\mathrm{EE} \quad=$ Spektrum efek eritemal

I $\quad=$ Spektrum intensitas sinar

Abs = Serapan bahan tabir surya

$\mathrm{CF} \quad=$ Faktor koreksi $(=10)$

Nilai EE $\times$ I telah ditentukan oleh Sayre (1979) adalah konstan dari panjang gelombang 290-320 nm dengan interval $5 \mathrm{~nm}$. Nilai EE $\times$ I dapat dilihat pada tabel 2.

Tabel 2. Nilai EE $\times$ I

\begin{tabular}{cc}
\hline Panjang Gelombang $(\mathrm{nm})$ & $\mathrm{EE} \times \mathrm{I}$ \\
\hline 290 & 0,015 \\
295 & 0.0817 \\
300 & 0,2874 \\
305 & 0,3278 \\
310 & 0,1864 \\
315 & 0,0839 \\
320 & 0,018 \\
\hline
\end{tabular}

Keefektivan tabir surya ditentukan dengan nilai SPF yang dikelompokan berdasarkan klasifikasi yang telah ditetapkan oleh Food and Drug Administration (FDA). Keefektivan tabir surya berdasarkan penilaian SPF ditentukan berdasarkan katagori yang dikeluarkan oleh FDA, dapat dilihat pada tabel 3. 
Tabel 3. Penilaian SPF menurut Food and Drug Administration (2013)

\begin{tabular}{cc}
\hline Tipe Proteksi & Nilai SPF \\
\hline Proteksi Minimal & $1-4$ \\
Proteksi Sedang & $4-6$ \\
Proteksi Ekstra & $6-8$ \\
Proteksi Maksimal & $8-15$ \\
Proteksi Ultra & $>15$ \\
\hline
\end{tabular}

\section{HASIL DAN PEMBAHASAN}

Libo merupakan salah satu tumbuhan yang merupakan sumber antioksidan yang potensial (Rijai, 2013), karena memiliki kandungan metabolit sekunder seperti fenol, flavonoid, alkaloid dan steroid atau triterpenoid (Febrina, 2015; Rusli, 2015). Senyawasenyawa bahan alam yang memiiki aktivitas antioksidan biasanya bertanggung jawab untuk melindungi tanaman dari pengaruh sinar buruk sinar UV (Amrillah, 2015). Profil aktivitas tabir surya fraksi $n$-heksana buab Libo berdasarkan \%Te dan \% Tp disajikan dalam tabel 4.

Tabel 4. Profil Tabir Surya Fraksi $n$-heksana Buah Libo

\begin{tabular}{ccccc}
\hline $\begin{array}{c}\text { [Fraksi }] \\
(\mathbf{~ p p m})\end{array}$ & $\begin{array}{c}\text { Persen Te } \\
(\boldsymbol{\%})\end{array}$ & $\begin{array}{c}\text { Profil Tabir } \\
\text { Surya }\end{array}$ & $\begin{array}{c}\text { Persen } \\
\text { Tp }(\boldsymbol{\%})\end{array}$ & $\begin{array}{c}\text { Profil Tabir } \\
\text { Surya }\end{array}$ \\
\hline $50 \mathrm{ppm}$ & 39,96 & - & 22,03 & Sunblock \\
$100 \mathrm{ppm}$ & 20,79 & - & 7,06 & Sunblock \\
$150 \mathrm{ppm}$ & 11,26 & Suntan Standar & 2,78 & Sunblock \\
$200 \mathrm{ppm}$ & 6,89 & Suntan Standar & 1,48 & Sunblock \\
$250 \mathrm{ppm}$ & 6,32 & Suntan Standar & 1,68 & Sunblock \\
$300 \mathrm{ppm}$ & 4,93 & Proteksi Ekstra & 1,65 & Sunblock \\
$400 \mathrm{ppm}$ & 3,01 & Proteksi Ekstra & 1,21 & Sunblock \\
\hline
\end{tabular}

Berdasarkan tabel 4, \% Te fraksi $n$-heksana buah Libo pada konsentrasi 150 dan 200 ppm memiliki profil kategori aktivitas tabir surya sebagai suntan standar. Suntan standar adalah kategori penilaian aktivitas tabir surya dimana suatu bahan mampu mencegah sengatan sinar matahari dengan mengabsorbsi kurang dari $85 \%$ atau lebih radiasi UV B pada panjang gelombang 290 hingga $320 \mathrm{~nm}$ sehingga bahan ini dapat menyebabkan sedikit eritema tanpa menimbulkan rasa sakit yang memiliki kemampuan untuk memproteksi kulit normal atau yang tidak sensitif (Wikinson dan Moore, 1982; Cumpelik, 1972). Sedangkan pada konsentrasi 300 dan 400 ppm, \%Te fraksi $n$-heksana buah libo memiliki profil kategori proteksi ekstra. Proteksi ekstra adalah kategori penilaian aktivitas tabir surya dimana suatu bahan mampu mencegah sengatan sinar matahari dengan mengabsorbsi 95\% atau lebih radiasi sinar UV pada panjang gelombang 290 hingga $320 \mathrm{~nm}$. (Wikinson dan Moore, 1982). Kategori suntan memiliki kemampuan untuk melindungi kulit yang lebih sensitif terhadap sengatan sinar matahari (Cumpelik, 1972). 
Berdasarkan tabel 4, profil tabir surya fraksi $n$-heksana buah Libo berdasarkan penilaian \% Tp termasuk kategori perlindungan Sunblock pada semua konsentrasi uji. Sunblock adalah kategori penilaian aktivitas tabir surya dimana suatu bahan memiliki kemampuan untuk mampu mencegah sengatan sinar matahari dari pengaruh radiasi sinar UV A dan UV B (Cumpelik, 1972). Dengan demikian dapat dikatakan bahwa bahwa fraksi $n$-heksana buah Libo memiliki aktivitas tabir surya.

Untuk melihat efektivitas tabir surya fraksi $n$-heksana buah Libo dilakukan dengan menghitung niai Sun Protection Factor (SPF). SPF merupakan indikator universal yang menjelaskan tentang keefektifan dari suatu produk atau zat yang bersifat UV protektor, dimana semakin tinggi nilai SPF dari suatu produk atau zat aktif tabir surya maka semakin efektif untuk melindungi kulit dari pengaruh buruk sinar UV (Dutra et al., 2004). Nilai SPF fraksi $n$-heksana buah Libo disajikan pada tabel 5 .

Tabel 5. Kategori Efektivitas Tabir Surya Fraksi $n$-heksana Buah Libo

\begin{tabular}{ccc}
\hline $\begin{array}{c}\text { [Fraksi] } \\
\text { ( ppm) }\end{array}$ & Nilai SPF & Kategori Efektivitas Tabir Surya \\
\hline 50 & 5,51 & Proteksi sedang \\
100 & 10,04 & Proteksi maksimal \\
150 & 13,65 & Proteksi maksimal \\
200 & 16,34 & Proteksi Ultra \\
250 & 18,68 & Proteksi Ultra \\
300 & 20,13 & Proteksi Ultra \\
400 & 20,69 & Proteksi Ultra \\
\hline
\end{tabular}

Berdasarkan tabel 5, terlihat bahwa Nilai SPF fraksi n-heksana buah libo berada pada rentang $5-20$, yang berarti bahwa fraksi n-heksana buah libo memiliki efektivitas sedang hingga proteksi ultra sebagai tabir surya. Fraksi $n$-heksana buah Libo memiliki nilai SPF terendah pada konsentrasi 50 ppm dengan kategori efektivitas proteksi sedang dan tertinggi pada konsentrasi 300 dan 400 ppm yaitu sebesar 20,13\% dan 20,69\% dengan kategori efektivitas tabir surya proteksi ultra. Fraksi $n$-heksana buah Libo memiliki kemampuan untuk dapat melindungi kulit dari radiasi buruk sinar UV.

\section{KESIMPULAN}

Fraksi $n$-heksana buah Libo (Ficus variegata Blume.) memiliki kemampuan untuk melindungi kulit dari pengaruh buruk sinar UV dengan konsentrasi terbaik untuk kategori tabir surya fraksi $n$-heksana adalah 300 dan 400 ppm berdasarkan nilai $\%$ Te dan $\%$ Tp dan berdasarkan nilai SPF $>20$ termasuk ke dalam kategori proteksi ultra dalam efektivitas tabir surya. 


\section{DAFTAR PUSTAKA}

Amrillah, M. S., Rusli, R., Fadraersada, J., 2015. Aktivitas Tabir Surya daun Miana (Coleus atropurpureus L. Benth). Jurnal Sains dan Kesehatan. 1 (4). 168-174. DOI: https://doi.org/10.25026/jsk.v1i4.35

Balsam, M. S., \& Sagarin, E. (Eds.). 1972. Cosmetics: Science and Technology $2^{\text {nd }}$ Ed., Vols. 1-3. Interscience Publishers, Inc: New York.

Budiarso et al., 2015. Sunscreen Activity of Phenolic of Piper miniatum . BI fruit. Journal of Chemistry. 8 (2). 30-37.

Dutra, EA., Oliveira DAGC, Kedor-Hackmann ERM, Santoro MIRM. 2004. Determination of Sun protection Factor (SPF) of sunscreens by ultraviolet spectrophotometry. Brazilian Journal of Pharmaceutical Sciences. 4 No 3. 381-385.

Food and Drug Administration (FDA). 2003. Guidance for Industry Photosafety Testin. Pharmacology Toxycology Coordinating Committee in the Centre for Drug Evaluation and Research (CDER) at the FDA.

Febrina, L., Rusli, R., Muflihah, F., 2015. Optimalisasi Ekstraksi Dan Uji Metabolit Sekunder Tumbuhan Libo (Ficus Variegata Blume.). Journal Tropical Pharmacy and Chemistry. 3. (2). 74-81. DOI: https://doi.org/10.25026/jtpc.v3i2.153

Hadinoto, I., Soeratri W., dan Meity, C. T., 2000. Pengaruh pH terhadap Efektivitas Sediaan Tabir Matahari dengan Bahan Aktif Etil Heksil pMetoksinamat dan Oksilbenzen dalam Basis Hidrofilik Krim secara In Vitro. Kongres Ilmiah XIII Ikatan Sarjana Farmasi Indonesia. Kumpulan Makalah: Jakarta.

Handayani, S. 2009. Sintesis Senyawa Dibenzalaseton. Universitas Negeri Yogyakarta. Yogyakarta.

Rusli, R., Hardina, M. P., Muflihah, F., Rahmadani, A., 2015. Profil Kromatografi Senyawa Aktif Antioksidan dan Antibakteri Fraksi $n$-Heksana Dan Libo (Ficus variegata Blume.) Journal Tropical Pharmaceutical Chemistry. 3 (2). 124-130. DOI: https://doi.org/10.25026/jtpc.v3i2.98

Mansur, JS., Breder MNR, Mansur MCA, Azulay RD. 1986. Determination of Sun Protection Factor Volume 61. An. Bras. Dermatol. 61. 121-124.

Rijai, L. 2013. Potensi Tumbuhan Libo (Ficus variegata Blume) Sebagai Sumber Bahan Farmasi Potensial. Journal Tropical Pharmaceutical Chemistry. 2. (3). 166-179. DOI: $\underline{\text { https://doi.org/10.25026/jtpc.v2i3.63 }}$

Sayre, R.M., P.P. Agin., G.J. Levee., dan E. Marlowe. 1979. A Comparison of In Vivo and In Vitro Testing Sunscreening Formulas. Photochem. Photobiol. 29. 559-566. 
WHO. 2008. Cancer Key Fact (Global Burden of Cancer). http://who.Int/cancer /en/index.html. 16 Maret 2016.

Wilkinson, J. B. dan Moore, R. J. 1982. Harry's Cosmeticology, 7th Ed. George Godwin. London. 